\title{
Erratum to: Contextual effects in interval-duration judgements in vision, audition and touch
}

\author{
David Burr • Eleonora Della Rocca •
}

M. Concetta Morrone

Published online: 18 August 2013

(C) Springer-Verlag Berlin Heidelberg 2013

\section{Erratum to: Exp Brain Res}

\section{DOI 10.1007/s00221-013-3632-z}

In the original publication of the article, the name of the second author is incorrectly given in the affiliations section. The correct name should read E. Della Rocca and not E. D. Rocca.

The online version of the original article can be found under doi:10.1007/s00221-013-3632-z.

D. Burr $(\bowtie) \cdot$ E. Della Rocca

Department of Neuroscience, Psychology, Pharmacology

and Child Health, University of Florence, Florence, Italy

e-mail: dave@in.cnr.it

D. Burr

Neuroscience Institute, National Research Council, Pisa, Italy

D. Burr · M. C. Morrone

Robotics and Cognitive Sciences Department, Italian Institute

of Technology, Genoa, Italy

\section{C. Morrone}

Department of Translational Research on New Technologies

in Medicine and Surgery, University of Pisa, Pisa, Italy

M. C. Morrone

Stella Maris Foundation, Pisa, Italy 